\title{
Insulin secretory responses to rising and falling glucose concentrations are delayed in subjects with impaired glucose tolerance
}

\author{
D. A. Ehrmann ${ }^{1}$, E. Breda ${ }^{2}$, M.K. Cavaghan ${ }^{1}$, S. Bajramovic ${ }^{1}$, J. Imperial ${ }^{1}$, G. Toffolo ${ }^{2}$, C. Cobelli ${ }^{2}$, K.S. Polonsky ${ }^{3}$ \\ ${ }^{1}$ Department of Medicine, Section of Endocrinology, The University of Chicago Pritzker School of Medicine, Chicago, Illinois, \\ USA \\ ${ }^{2}$ Department of Electronics and Informatics, University of Padua, Padua, Italy \\ ${ }^{3}$ Department of Medicine, Washington University School of Medicine, St. Louis, Missouri, USA
}

\section{Abstract}

Aims/hypothesis. We hypothesized that beta-cell responses to changes in glucose would not be normal in subjects with impaired glucose tolerance (IGT).

Methods. Three groups of 6 subjects were studied: normal weight with normal glucose tolerance (control subjects); obese with normal glucose tolerance (Obese-NGT); and obese with IGT (Obese-IGT). All subjects had a graded glucose infusion protocol to increase (step-up) and then decrease (step-down) plasma glucose. We obtained average insulin-secretion rates (ISR) over the glucose range common to all three groups during step-up and step-down phases, minimal model indices of beta-cell function $\left(\phi_{\mathrm{b}}, \phi_{\mathrm{d}}, \phi_{\mathrm{s}}\right.$, $\left.\mathrm{T}_{\text {up }}, \mathrm{T}_{\text {down }}\right)$, and insulin sensitivity ( $\mathrm{Si}$ ).

Results. ISR differed significantly between step-up and -down phases only in Obese-IGT individuals. Basal $\left(\phi_{\mathrm{b}}\right)$ and stimulated $\left(\phi_{\mathrm{d}}, \phi_{\mathrm{s}}\right)$ beta-cell sensitivity to glucose were similar in the three groups. Delays between glucose stimulus and beta-cell response during both step-up $\left(\mathrm{T}_{\mathrm{up}}\right)$ and -down $\left(\mathrm{T}_{\text {down }}\right)$ phases were higher in Obese-IGT compared to Controls and Obese-NGT individuals. The product ISR $\times \mathrm{Si}$ $\left(10^{-5} \mathrm{~min}^{-2} \times 1\right)$ was lower in Obese-IGT compared to Controls, both during step-up $(919 \pm 851$ vs $3192 \pm 1185, p<0.05)$ and step-down $(1455 \pm 1203$ vs $3625 \pm 691, p<0.05)$ phases. Consistently, the product $\phi_{\mathrm{s}} \times \mathrm{Si}\left(10^{-14} \mathrm{~min}^{-2} \cdot \mathrm{pmol}^{-1} \times 1\right)$ was lower in $\mathrm{Ob}-$ ese-IGT than in control subjects $(27.6 \pm 25.4$ vs $103.1 \pm 20.2, p<0.05)$.

Conclusion/interpretation. Subjects with IGT are not able to secrete insulin to compensate adequately for insulin resistance. They also show delays in the timing of the beta-cell response to glucose when glucose levels are either rising or falling. [Diabetologia (2002) 45:509-517]

Keywords Minimal model, insulin secretion, impaired glucose tolerance, pancreatic beta cell.
Received: 30 July 2001 and in revised form: 21 November 2001

Corresponding author: D. A. Ehrmann MD, Department of Medicine, Section of Endocrinology, The University of Chicago Pritzker School of Medicine, 5841 South Maryland Avenue, MC 1027, Chicago, IL 60637, USA,

e-mail: dehrmann@medicine.bsd.uchicago.edu

Abbreviations: ANOVA, Analysis of variance; IGT, impaired glucose tolerance; IVGTT, intravenous glucose tolerance test; NGT, normal glucose tolerance; ISR, insulin secretion rate; $\phi_{\mathrm{b}}$, basal beta-cell sensitivity to glucose; $\phi_{\mathrm{d}}$, dynamic sensitivity to glucose; $\phi_{\mathrm{s}}$, static sensitivity to glucose; $\mathrm{T}_{\mathrm{up}}$, delay between glucose stimulus and beta-cell response in the step-up phase; $\mathrm{T}_{\text {down }}$, delay between glucose stimulus and beta-cell response in the step-down phase; $\mathrm{Si}$, insulin sensitivity
Impaired glucose tolerance (IGT) is defined by an increase in plasma glucose in response to an oral glucose challenge to levels intermediate between normal and diabetic [1] and is a risk factor for the subsequent development of diabetes [2]. The transition from normal glucose tolerance to IGT is characterized by a reduction in the ability of the pancreatic beta cell to sustain its compensatory response to insulin resistance [3]. When compared to subjects with normal glucose tolerance, those with IGT have a blunted insulin secretory response to the rise in glucose during a rapidly sampled intravenous glucose tolerance test (IVGTT) and a shift to the right in the dose-response curve relating the plasma glucose concentration to the insulin secretion rate $[4,5]$. IGT is additionally 
characterized by an alteration in the ability of the beta cell appropriately to detect and respond to oscillations in plasma glucose [6-8]. An important component of the glucose sensing function of the pancreatic beta cell is its ability to reduce insulin secretion appropriately in response to a fall in the plasma glucose concentration. This aspect of beta-cell function has not been specifically tested in subjects with IGT.

Our study was thus undertaken to test the hypothesis that the response of the pancreatic beta cell to a falling glucose concentration would differ from normal in subjects with IGT. An experimental protocol was developed in which insulin secretion and betacell sensitivity to glucose are examined under two distinct physiologic conditions: when glucose concentrations are raised in a stepwise fashion (step-up) and then progressively lowered (step-down). This experimental design, which also provides an index of whole body insulin sensitivity, has been recently validated in subjects with normal glucose tolerance [9]. Here we compare insulin secretory responses to a step-up and step-down glucose infusion protocol in subjects with IGT to the responses in lean and obese subjects with normal glucose tolerance.

\section{Subjects and methods}

Selection and definition of study subjects. Three groups of subjects were studied: normal weight with normal glucose tolerance (Control; $n=6$ ); obese with normal glucose tolerance (Obese-NGT; $n=6$ ); and obese with IGT (Obese-IGT; $n=6$ ).

Exclusion criteria included the use of medications known to alter insulin secretion or action, endocrinopathies including Cushing's syndrome, or thyroid dysfunction. Women with a history of gestational diabetes were excluded.

All protocols were approved by the Institutional Review Board of The University of Chicago. Written informed consent was obtained from each subject.

Because of the possible effect of variations in insulin secretion at different phases of the menstrual cycle [10,11], women were studied in the follicular phase (day 1-8).

Experimental protocols. Studies were carried out after an overnight fast. Intravenous catheters were placed into antecubital veins. Where appropriate, one catheter was used to give intravenous glucose, while the catheter in the contralateral forearm was used for blood sampling. The blood sampling arm was heated to obtain arterialized venous samples.

Oral glucose tolerance test (OGTT). Blood samples were obtained at baseline and at $30 \mathrm{~min}$ intervals for $3 \mathrm{~h}$ to measure glucose and insulin following ingestion of a $75 \mathrm{~g}$ glucose load. Glucose tolerance was evaluated using the criteria of the American Diabetes Association [1].

Graded glucose infusion protocol. Glucose was infused over seven 40-min periods. The first half of the study was designed to achieve a progressive increase (step-up) in the plasma glucose concentration by infusion of glucose at rates of $0,4,8$, and $16 \mathrm{mg} \cdot \mathrm{kg}^{-1} \cdot \mathrm{min}^{-1}$. The infusion rate was then reduced (step-down) from 16 to $8,4,0 \mathrm{mg} \cdot \mathrm{kg}^{-1} \cdot \mathrm{min}^{-1}$. Blood was sam- pled every $10 \mathrm{~min}$ during the protocol, beginning $30 \mathrm{~min}$ before initiation of the glucose infusion, for measurement of glucose, insulin, and C-peptide concentrations.

Data analysis and statistical methods. Insulin secretion was derived using two distinct methods, namely deconvolution of $\mathrm{C}$ peptide concentrations and minimal models of C-peptide secretion and kinetics. The latter method also allows for the derivation of indices of beta-cell function, as described below. Insulin sensitivity, on the other hand, was derived using the minimal model of glucose disposal [12].

Deconvolution. Standard parameters for C-peptide kinetics [13] were utilized to derive insulin secretory rates (ISR's) from the plasma $\mathrm{C}$-peptide concentrations by deconvolution as previously described [14]. The C-peptide profiles were smoothed with a 2-point moving average before calculating the ISR's. The mean ISR's were calculated over the interval of plasma glucose achieved during the step protocol that was common to all subjects, ie., 8 to $14 \mathrm{mmol} / \mathrm{l}$ during the step-up and 14 to $8 \mathrm{mmol} / \mathrm{l}$ during the step-down.

Minimal models of C-peptide secretion and kinetics. Insulin secretion was also quantified using minimal models of C-peptide secretion and kinetics originally proposed to describe IVGTT data [15] and recently extended to graded glucose infusion experiments [9] and oral glucose tolerance tests [16]. Briefly, insulin secretion is described as the sum of two components, related to both the production of new insulin and to the secretion of stored insulin. The former is controlled by the concentration of glucose and is referred to as the static glucose control, while the latter is controlled by the rate of increase of glucose concentration, and is referred to as the dynamic glucose control. By using standard parameters for C-peptide kinetics [13], minimal models of $\mathrm{C}$-peptide secretion can then be numerically identified from C-peptide and glucose concentrations and the time course of ISR can be reconstructed. In addition, indices of beta-cell function can be quantified in both the static and dynamic phases, as detailed below.

The static sensitivity to glucose $\phi \mathrm{s}=\beta\left(10^{-9} \mathrm{~min}^{-1}\right)$ quantifies the effect of glucose on beta-cell secretion of new insulin, coming from insulin production. It measures the ratio at steady state of insulin secretion rate (expressed as deviation from basal per unit $\mathrm{C}$-peptide distribution volume $\left(\mathrm{V}_{1}\right)$ to glucose). Of note, the steady state relationship between insulin secretion rate and glucose is not derived directly from the data but is inferred from non-steady state data. The minimal model assumes a linear relationship between ISR ( $\mathrm{pmol} / \mathrm{min}$ ) at steady state (denoted by subscript ss) and glucose concentration $\mathrm{G}$ ( $\mathrm{mmol} /$ 1):

$$
I S R_{s s}=I S R_{b}+\beta \cdot V_{1} \cdot\left(G_{s s}-G_{b}\right)
$$

and provides reliable estimates of parameter $\beta 10^{-9} \mathrm{~min}^{-1}$ which measures the stimulatory effect of a glucose stimulus on beta-cell secretion at steady state, from non-steady state data.

Three indices are derived during the dynamic phase. These are the dynamic sensitivity to glucose, $\phi_{\mathrm{d}}$, and the response times of the beta cell to the glucose stimulus for both phases of the infusion protocol, i. e., step-up and step-down. More specifically, the dynamic sensitivity to glucose, $\phi_{\mathrm{d}}\left(10^{-9}\right)$, is a measure of the stimulatory effect of the rate at which glucose increases upon the secretion of stored insulin, which is active when glucose concentration increases (step-up) but absent when glucose decreases (step-down). The response time during the step-up and the step-down phases $\left(\mathrm{T}_{\text {up }}(\mathrm{min})\right.$ and $\mathrm{T}_{\text {down }}$ 
(min) respectively) serves as a measure of the time lag between glucose stimulus and insulin secretory response. The shorter the response times, the more closely beta-cell secretion parallels the glucose stimulus. In the down portion of the experiment, all secreted insulin comes from production of new insulin. Therefore the response time $\mathrm{T}_{\text {down }}$ is the delay between glucose stimulus and production of new insulin. In the step-up portion of the experiment, insulin secretion is due not only to the production of new insulin but also to the secretion of additional insulin coming from insulin storage in beta cells [17]. This process accelerates the rate at which insulin secretion increases and results in an equivalent reduction of the response time $\mathrm{T}_{\mathrm{up}}$, which depends on the magnitude of the dynamic sensitivity $\phi_{\mathrm{d}}$ compared to the static sensitivity $\phi_{\mathrm{s}}[9]$. If $\phi_{\mathrm{d}}$ increases compared to $\phi_{\mathrm{s}}$, the equivalent response time $\mathrm{T}_{\mathrm{up}}$ could be close to zero or even negative, indicating that insulin secretion increases even more rapidly than the glucose stimulus.

Basal. The sensitivity of the beta cell to glucose under basal conditions, $\phi_{\mathrm{b}}\left(10^{-9} \mathrm{~min}^{-1}\right)$, is defined as the ratio between basal insulin secretion rate (normalized by the C-peptide distribution volume) and basal glucose concentration.

Minimal model of glucose disposal. The minimal model of glucose disposal [12] was applied to glucose and insulin concentrations and an estimate of insulin sensitivity ( $\mathrm{Si}\left(10^{-5} \mathrm{~min}^{-1}\right.$. pmol $\cdot 1)$ ) was derived for each subject.

Adjustment of insulin secretion for the degree of insulin sensitivity. A number of parameters (so-called disposition indices) were derived to adjust the measures of insulin secretion for the degree of insulin sensitivity. These parameters are analogous to the disposition indices defined for the frequently sampled IVGTT protocol as the product of $\mathrm{Si}$ and parameters of beta-cell function, either the acute insulin response to glucose [19] or model derived beta-cell sensitivities [20]. The following disposition indices have been derived in the present study using the Si obtained from the minimal model analyses and distinct measures of beta-cell function as indicated: firstly, $\mathrm{Si} \times$ [mean ISR over the range $8-14 \mathrm{mmol} / 1$ glucose during the step-up phase]; secondly, $\mathrm{Si} \times$ [mean ISR over the range 14-8 mmol/l glucose during the step-down phase]; thirdly, $\mathrm{Si} \times\left[\phi_{\mathrm{d}}\right]$; fourthly, Si $\times\left[\phi_{\mathrm{s}}\right]$.

Statistical analysis. The significance of differences between groups was determined by analysis of variance (ANOVA) with Tukey-Kramer post-hoc correction for multiple comparisons. Data that were not normally distributed were logarithmically-transformed. For all analyses, a two-tailed $p$ value of less than 0.05 was considered to be statistically significant. Unless otherwise noted, all results are expressed as means \pm SD. Statistical analysis was done using StatView 5.0 (SAS Institute, Cary, N. C., USA).

Model identification. Model parameters were estimated, together with a measure of their precision, by non-linear least squares [21, 22] using SAAM II, a software programme designed to simulate and fit compartmental models to data [17]. Measurement errors have been assumed to be independent and Gaussian, with zero mean. Errors in C-peptide measurements were assumed with a constant but unknown variance; errors in glucose measurement with a Fractional Standard Deviation (FSD) equal to $1.5 \%$.

Assay methods. Plasma glucose was measured immediately using a glucose analyzer (YSI Model 2300 STAT, Yellow Springs Instruments, Yellow Springs, Ohio, USA). The coefficient of
Table 1. Clinical characteristics of study subjects and parameters calculated during the OGTT

\begin{tabular}{lccc}
\hline & $\begin{array}{l}\text { Control } \\
(n=6)\end{array}$ & $\begin{array}{l}\text { Obese-NGT } \\
(n=6)\end{array}$ & $\begin{array}{l}\text { Obese-IGT } \\
(n=6)\end{array}$ \\
\hline Clinical characteristics of study subjects & \\
Age (years) & $27.8 \pm 4.5$ & $34.3 \pm 11.7$ & $36.7 \pm 5.9$ \\
Weight $(\mathrm{kg})$ & $66.5 \pm 9.9$ & $96.9 \pm 16.2^{\mathrm{a}}$ & $104.6 \pm 13.9^{\mathrm{a}}$ \\
BMI $\left(\mathrm{kg} / \mathrm{m}^{2}\right)$ & $22.8 \pm 1.8$ & $36.7 \pm 7.1^{\mathrm{a}}$ & $36.7 \pm 4.9^{\mathrm{a}}$ \\
Sex $(\mathrm{m} / \mathrm{f})$ & $2 / 4$ & $1 / 5$ & $2 / 4$ \\
Glyco HB $(\%)$ & $4.9 \pm 0.6$ & $5.1 \pm 0.5$ & $6.0 \pm 0.6^{\mathrm{a}}$
\end{tabular}

Oral glucose tolerance test

Fasting glucose

$(\mathrm{mmol} / \mathrm{l})$

Fasting insulin

$(\mathrm{pmol} / \mathrm{l})$

Fasting C-peptide (pmol/l)

2-h glucose $(\mathrm{mmol} / \mathrm{l})$

\section{9}

$9 \pm 0.3 \quad 5.0 \pm 0.3 \quad 5.3 \pm 0.5$

2-h insulin ( $\mathrm{pmol} / \mathrm{l})$

$77 \pm 46$

$$
125 \pm 77
$$

$164 \pm 87$

Glucose AUC

$(\mathrm{mmol} \cdot \mathrm{min} / \mathrm{l})$

Insulin AUC

$\left(10^{3} \mathrm{pmol} \cdot \mathrm{min} / \mathrm{l}\right)$

$$
568 \pm 296
$$

$603 \pm 347$

$963 \pm 567$

$5.9 \pm 0.7$

$6.6 \pm 0.7$

$9.4 \pm 1.1^{\mathrm{a}, \mathrm{b}}$

$247 \pm 74$

$637 \pm 356^{\mathrm{a}}$

$830 \pm 253^{\mathrm{a}}$

$p<0.05$ ANOVA (Tukey-Kramer)

${ }^{\mathrm{a}}$ vs Control

${ }^{\mathrm{v}}$ vs Obese-NGT

variation of this method is less than $2 \%$. Glycosylated haemoglobin was measured by boronate affinity chromatography with an intra-assay coefficient of variation of $4 \%$ (BioRad, Hercules, Calif., USA). Serum insulin was assayed by a double antibody technique [23] with a lower limit of sensitivity of 20 $\mathrm{pmol} / \mathrm{l}$ and an average intraassay coefficient of variation of $6 \%$. The cross reactivity of proinsulin in the radioimmunoassay for insulin is approximately $40 \%$. Plasma C-peptide was measured as previously described [24]. The lower limit of sensitivity of the assay is $0.02 \mathrm{pmol} / \mathrm{ml}$ and the intraassay coefficient of variation averaged $6 \%$.

\section{Results}

Clinical characteristics of study subjects. There was no statistical difference in the mean age of the subjects in each of the three study groups (Table 1). By design, both body weight and BMI were significantly higher in the obese subjects than in control subjects: the mean BMI of the Obese-NGT group was $36.7 \pm 7.1$ $\mathrm{kg} / \mathrm{m}^{2}$ and that of the Obese-IGT group was $36.7 \pm 4.9 \mathrm{~kg} / \mathrm{m}^{2}$, compared to Control subjects whose mean was $22.8 \pm 1.8 \mathrm{~kg} / \mathrm{m}^{2}$ (Table 1). Of note, the $\mathrm{Ob}-$ ese-NGT and Obese-IGT groups had virtually identical mean values for BMI.

Metabolic characteristics of study subjects. All subjects had normal (less than $7.2 \%$ ) glycosylated haemoglobin concentrations; the range was 4.1 to $7.0 \%$. While still within the normal range, the mean glycosylated haemoglobin concentration was highest in the 

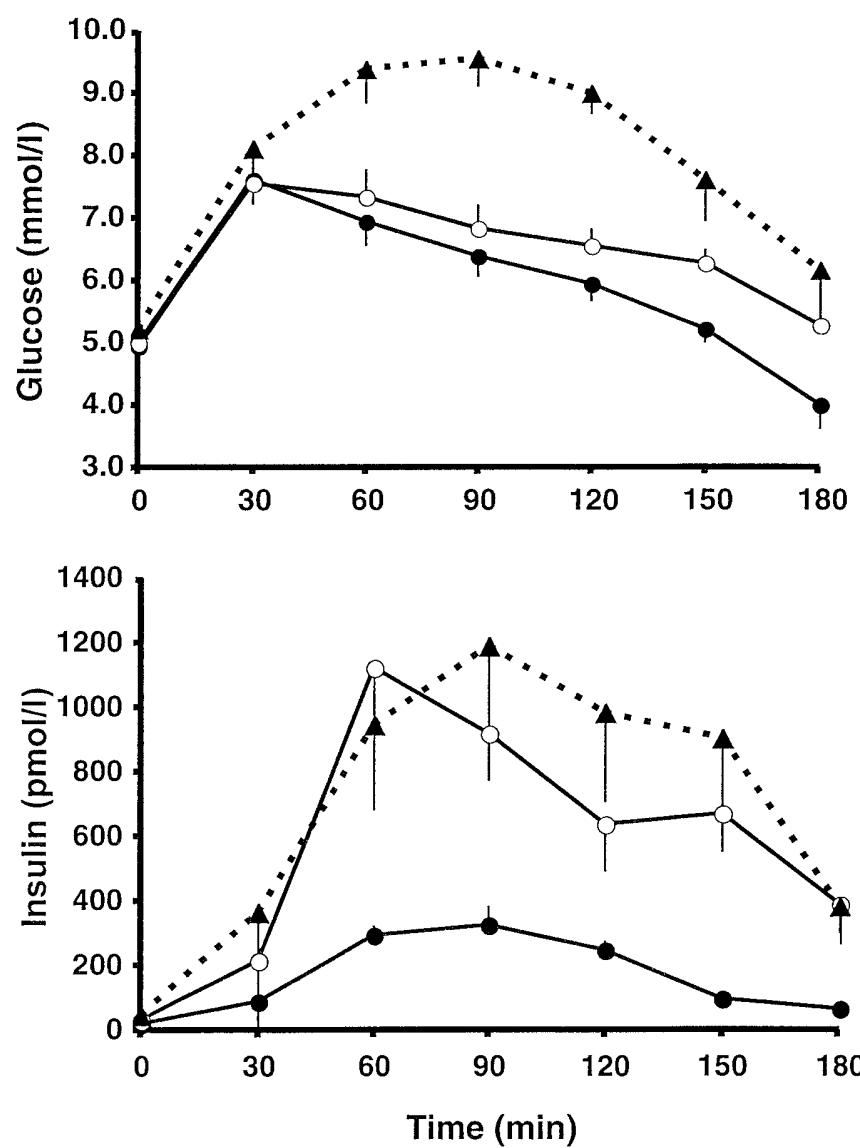

Fig.1. Glucose (upper panel) and insulin (lower panel) levels obtained in response to administration of a standard $75 \mathrm{~g}$ oral glucose load in lean (Controls) and obese subjects with normal glucose tolerance (Obese-NGT) and obese subjects with impaired glucose tolerance (Obese-IGT). There was no difference between groups in either the fasting glucose or fasting insulin levels. The insulin secretory response was, however, significantly higher in the obese subjects with normal (ObeseNGT) or impaired (Obese-IGT) glucose tolerance compared to lean controls (Controls). The insulin response was virtually identical in the two obese groups. Data are means \pm SEM. Controls (- - $)$; Obese-NGT (- - -); Obese-IGT $\left(---\boldsymbol{\Delta}^{---)}\right.$

Obese-IGT subjects $(6.0 \pm 0.6 \%)$. This concentration was higher than that observed in Controls $(4.9 \pm 0.6 \% ; p<0.05)$, but was not different from that seen in Obese-NGT subjects $(5.1 \pm 0.5 \%, p=\mathrm{NS})$.

Glucose and insulin concentrations measured during the oral glucose tolerance test are shown in Fig. 1. The fasting glucose concentration was slightly, but not significantly, higher in the Obese-IGT group $(5.3 \pm 0.5 \mathrm{mmol} / \mathrm{l})$ compared to both Controls $(4.9 \pm 0.3 \mathrm{mmol} / \mathrm{l})$ and Obese-NGT subjects $(5.0 \pm 0.3 \mathrm{mmol} / \mathrm{l})$. In contrast, glucose concentrations at $2 \mathrm{~h}$ were, as expected, significantly higher in the Obese-IGT subjects $(9.4 \pm 1.1 \mathrm{mmol} / \mathrm{l})$ compared to both lean Controls $(5.9 \pm 0.7 \mathrm{mmol} / \mathrm{l} ; p<0.05)$ and Obese subjects with normal glucose tolerance $(6.6 \pm 0.7 \mathrm{mmol} / 1 ; p<0.05)$.
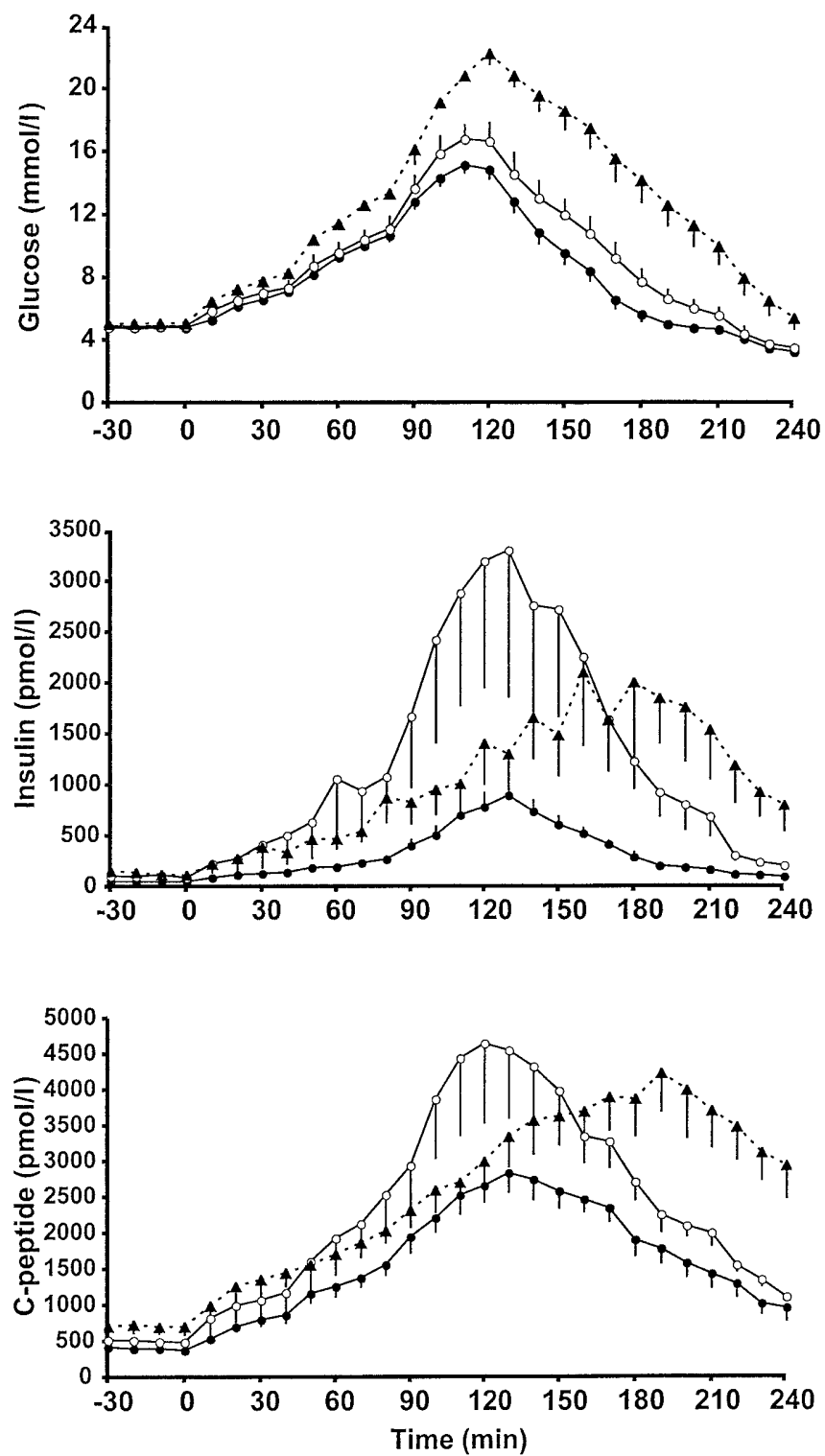

Fig. 2. Plots of glucose (top panel), insulin (center panel), and C-peptide (bottom panel) levels in response to a graded glucose infusion (step-study) protocol. Obese-IGT subjects demonstrate a distinctive pattern of insulin and C-peptide secretion in response to a falling plasma glucose concentration. Data are means \pm SEM. Controls (- - $)$; Obese-NGT (一-); Obese-IGT (- - $\mathbf{A}---)$

Fasting insulin concentrations were highly correlated with the BMI $(r=0.74 ; p<0.0005)$ across the cohort of 18 subjects studied. The mean fasting insulin concentrations, however, were not significantly different between groups. The area under the insulin curve was highest in the Obese-NGT group but was not significantly different from that in the ObeseIGT subjects (Table 1). Thus, when expressed in relation to the concentration of prevailing glucose, e.g., as the ratio of the area-under-the-insulin-curve to area-under-the-glucose-curve, the Obese-IGT subjects had a relative insulin deficiency when compared 
Table 2. Parameters and indices calculated during the step-study

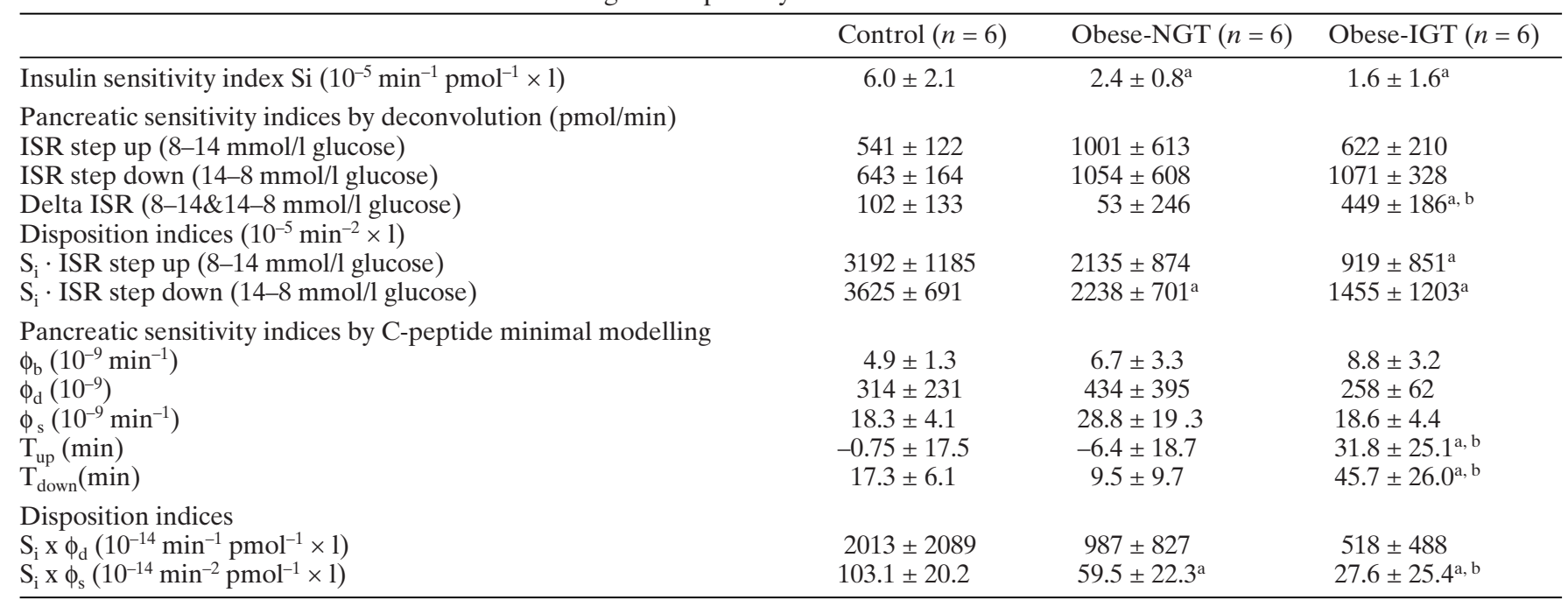

$p<0.05$ ANOVA (Tukey-Kramer)

${ }^{\mathrm{a}}$ vs Control

${ }^{\mathrm{b}}$ vs Obese-NGT

to the Control and Obese-NGT groups ( $p<0.05$; data not shown).

Assessment of insulin secretion from deconvolution. To allow insulin secretory responses to be compared over a standardized range of glucose concentrations, insulin secretion rates were derived over the interval from 8.0 to $14.0 \mathrm{mmol} / \mathrm{l}$ glucose for the step-up phase and 14.0 to $8.0 \mathrm{mmol} / \mathrm{l}$ for the step-down phase (Fig.2). Glucose concentrations over this range were consistently achieved in the three subject groups during the exogenous glucose infusions. The mean ISR over this interval did not differ significantly among groups for either the step-up or step-down periods (Table 2). The ISR during the step-down phase tended to be higher than that achieved during the step-up phase (Table 2), although the magnitude of the difference in ISR between phases (delta ISR) varied for each group. The difference in ISR between step-down and step-up phases was statistically significant only in the obese subjects with IGT $(1071 \pm 328 \mathrm{pmol} / \mathrm{min}$ during the step-down phase vs $622 \pm 210 \mathrm{pmol} / \mathrm{min}$ during the step-up phase; $p<0.05)$.

Assessment of insulin secretion from C-peptide minimal models. C-peptide minimal model predictions of ISR were compared to the ISR obtained by deconvolution. No significant differences were found between the results obtained with the two methods (not shown).

C-peptide minimal models also allowed us to estimate a number of parameters and indices describing beta-cell sensitivity to glucose in the different phases of insulin secretion.
The sensitivity of the beta cell to glucose was not statistically different in the three groups, in either the basal $\left(\phi_{\mathrm{b}}\right)$ or stimulated states $\left(\phi_{\mathrm{d}}\right.$ and $\left.\phi_{\mathrm{s}}\right)$. However, obese subjects with normal glucose tolerance had higher values for both $\phi_{\mathrm{d}}$ and $\phi_{\mathrm{s}}$, when compared to the other two groups.

The ability of the beta cell to respond to the change in glucose concentrations during both the step-up and the step-down phase of the protocol was substantially less in the Obese-IGT subjects as reflected in the response time parameters, $T_{\text {up }}$ and $\mathrm{T}_{\text {down }}$. During the step-up phase $\mathrm{T}_{\mathrm{up}}$ was significantly longer in the Obese-IGT $(31.8 \pm 25.1 \mathrm{~min})$ group when compared both to Controls $(-0.75 \pm 17.5 \mathrm{~min})$ and to Obese-NGT subjects $(-6.4 \pm 18.7 \mathrm{~min})$ in whom there was virtually no lag period. During the step-down phase, all three groups had a lag in the response to glucose $\left(\mathrm{T}_{\text {down }}\right)$, and the difference between

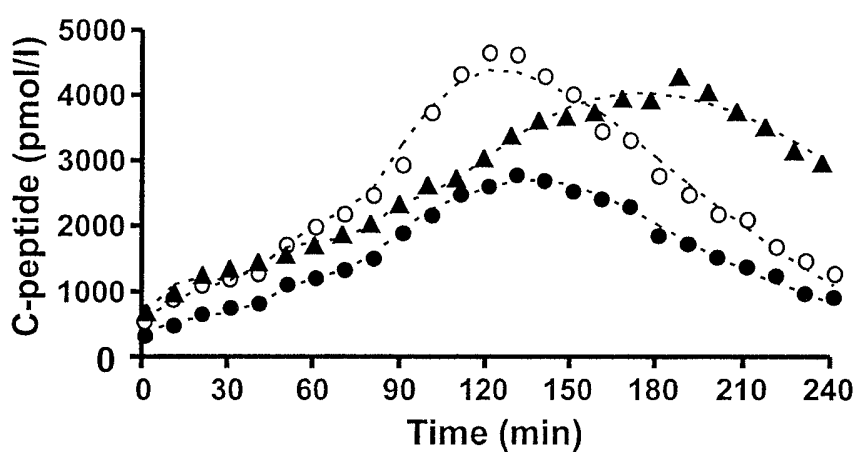

Fig.3. Average model fit of C-peptide data for each of the three groups. Note the unique pattern of secretion of C-peptide during the step-down phase in the Obese-IGT subjects. Controls (O); Obese-NGT ( $\bigcirc)$; Obese-IGT (A) 
Obese-IGT $(45.7 \pm 26.0 \mathrm{~min})$ and the groups with normal glucose tolerance was less pronounced but still statistically significant (Controls (17.3 \pm $6.1 \mathrm{~min})$; Obese-NGT (9.5 $\pm 9.7 \mathrm{~min})$ ) (Table 2). Average model fits of C-peptide for the three groups are represented in Fig. 3.

Insulin sensitivity. The index of insulin sensitivity $(\mathrm{Si})$ derived from insulin and glucose concentrations during the graded glucose infusions was highest in controls $\left(6.0 \pm 2.110^{-5} \mathrm{~min}^{-1} \cdot \mathrm{pmol} \cdot \mathrm{l}\right)$ and showed a progressive and statistically significant reduction with obesity (Obese-NGT: $2.4 \pm 0.810^{-5} \mathrm{~min}^{-1} \cdot \mathrm{pmol} \cdot 1$ ) and glucose intolerance (Obese-IGT: $1.6 \pm 1.6$ $\left.10^{-5} \mathrm{~min}^{-1} \cdot \mathrm{pmol} \cdot 1\right)($ Table 2$)$. There was, however, no significant difference in the index of insulin sensitivity between Obese-IGT and Obese-NGT groups.

Adjustment of insulin secretion by the degree of insulin sensitivity. When the ISRs were analysed in relation to the degree of insulin resistance, it became apparent that Obese-IGT subjects were less able to compensate for their insulin resistance. This finding was consistent using either deconvolution or C-peptide minimal model analysis.

Using deconvolution, a lower value for the disposition index $\mathrm{Si} \times$ ISR was observed among the ObeseIGT compared to the Obese-NGT (even if these differences did not reach statistical significance), both in the step-up and step-down phases (Table 2). Similarly, there was a significantly lower value for the disposition index $\mathrm{Si} \times$ ISR among Obese-IGT subjects compared to Controls, both in the step-up $(919 \pm 851$ vs $3192 \pm 1185 ; p<0.05)$ and in the step-down $(1455 \pm 1203$ vs $3625 \pm 691, p<0.05)$ phases (Table 2). Finally, obese subjects with normal glucose tolerance had lower disposition indices ( $\mathrm{Si} \times \mathrm{ISR}$ ) during both the step-up and the step-down phases when compared to controls, but this difference was statistically significant only during the step-down phase $(2238 \pm 701$ vs $3625 \pm 691, p<0.05)$ (Table 2$)$.

When C-peptide minimal models were used and $\phi_{\mathrm{d}}$ and $\phi_{\mathrm{s}}$ were adjusted for the degree of insulin resistance (obtaining $\mathrm{Si} \times \phi_{\mathrm{d}}$ and $\mathrm{Si} \times \phi_{\mathrm{s}}$ respectively), it was evident that Obese-IGT subjects were not able to compensate for their degree of insulin resistance. In addition, Obese-NGT subjects had higher (even if not significantly) disposition indices when compared to Obese-IGT, but lower disposition indices when compared to Controls. Differences between the Obese groups and the Control group emerged with the value of $\mathrm{Si} \times \phi_{\mathrm{s}}$ for the Obese-IGT group reduced to approximately $25 \%$ of the value in Controls $(27.6 \pm 25.4$ vs $103.1 \pm 20.2 ; p<0.05)$ (Table 2$)$.

\section{Discussion}

This study examined the possibility that in subjects with glucose intolerance, defects in the ability of the pancreatic beta cell to detect and respond to changes in plasma glucose might not be limited to periods when glucose levels are rising but might also extend to periods when glucose levels are falling. To address this, we used a recently developed protocol in which glucose levels are progressively increased over $2 \mathrm{~h}$ and then lowered over the same glucose range during the subsequent $2-\mathrm{h}$ period. This study design has a number of advantages over protocols in which the insulin secretory response to a rising glucose alone is evaluated. Specifically, this design allows the application of both deconvolution techniques and C-peptide minimal models as well as the glucose minimal model. Several findings have emerged from the present studies, even if the differences among groups are often just trends and are not statistically significant, because of the small sample size of each group.

Deconvolution enables derivation of insulin secretion rates in response to variation in glucose levels but no index of beta-cell function. When comparing different groups, it is necessary to compare insulin secretion either over the same temporal interval or over the same glucose range. In line with others [4, 25, 26], we adopted the second option, which considers insulin secretion to be more influenced by the glucose concentrations achieved than by the time in which they are achieved. Average ISR was thus calculated over the same glucose interval, i.e. 8-14 mmol/l. Deconvolution analysis of C-peptide concentrations revealed that obese subjects with impaired glucose tolerance have characteristic alterations in insulin secretion that distinguish them from lean and obese subjects with normal glucose tolerance. During the stepup phase (8-14 mmol glucose) the mean ISR was slightly higher in Obese-IGT subjects $(622 \pm 210$ $\mathrm{pmol} / \mathrm{min}$ ) than that observed in Controls with normal glucose tolerance $(541 \pm 122 \mathrm{pmol} / \mathrm{min})$, but substantially lower than that of Obese subjects with normal glucose tolerance $(1001 \pm 613 \mathrm{pmol} / \mathrm{min})$. In contrast, during the step-down phase (14-8 mmol glucose), Obese-IGT subjects had ISR's that were virtually identical to those of Obese-NGT subjects. Further, when comparing ISR's in the step-up phase to the step-down phase within each group, there was a quantitative and statistically significant difference in insulin secretion rates between phases in obese subjects with IGT that was not present in Controls or Obese-NGT subjects. When compared to the ISR during the step-up phase, the ISR during the stepdown phase was $72 \%$ higher in the Obese-IGT $(p<0.05)$ compared to $19 \%$ higher in Controls, and only $5 \%$ higher in Obese-NGT subjects.

However, with the present protocol steady-state conditions are not attained, and average ISR there- 
fore reflects pancreatic sensitivity to glucose but is also influenced by beta-cell response time to a glucose stimulus: average ISR can be lower due to either a decreased beta-cell sensitivity to glucose or to an increased delay in the response or to both. To overcome these limitations we used a new C-peptide minimal model [9] which, by postulating a specific glucose-insulin secretion functional relationship, allows one to quantify separately indices of beta-cell sensitivity to glucose (independent from the temporal interval and the glucose concentrations achieved) and the delay between the glucose stimulus and the secretory response. In particular the model differentiates the beta-cell response time during decreasing $\left(\mathrm{T}_{\text {down }}\right)$ and increasing $\left(\mathrm{T}_{\mathrm{up}}\right)$ steps, by assuming a dynamic glucose control able to accelerate the beta-cell response to an increasing glucose stimulus, as previously described [9]. C-peptide minimal model parameters show that obese-NGT subjects have higher static $\left(\phi_{\mathrm{s}}\right.$, Table 2$)$ and dynamic $\left(\phi_{\mathrm{d}}\right.$, Table 2$)$ sensitivities to glucose but similar response times $\left(\mathrm{T}_{\mathrm{up}}\right.$ and $\mathrm{T}_{\text {down }}$ ) when compared to controls. This means that the higher mean ISR during the step-up (8-14 mmol glucose, Table 2) and down phases (14-8 mmol glucose, Table 2) are actually due to a higher beta-cell sensitivity to glucose in this group.

Conversely Obese-IGT subjects have a similar static beta-cell sensitivity to glucose, $\phi_{\mathrm{s}}$, when compared to controls, but they have much higher response times, $\mathrm{T}_{\text {up }}$ and $\mathrm{T}_{\text {down }}$. This means that the substantially higher concentrations of insulin secreted in the down portion of the protocol does not reflect a higher beta-cell sensitivity to glucose but simply longer response times. This also explains the high delta ISR in the Obese-IGT subjects: even if average ISR is expressed over a similar plasma glucose range, i.e. $8-14 \mathrm{mmol} / \mathrm{l}$ during the step up and $14-8 \mathrm{mmol} / \mathrm{l}$ during the step down, the effective glucose stimulus is delayed with respect to plasma glucose by $30-45 \mathrm{~min}$, and thus is lower during the step up and higher during the step down. Controls and ObeseNGT subjects, on the other hand, have a lower delta ISR as their delays are shorter: in the step-up phase, there is no effective lag between glucose stimulus and insulin response, and there is a short delay, 10-20 min, during the step-down portion of the protocol. Conversely, the Obese-IGT subjects had response times threefold to fivefold greater than the lean and obese subjects, respectively, with normal glucose tolerance (Table 2). This quantitative difference is evident from the curves relating glucose to Cpeptide during the protocol (Fig. 2).

This finding of an apparent failure to appropriately reduce the rate of insulin secretion when glucose concentrations are declining could be the result of a defect in the feedback loop which couples glucose concentrations and insulin secretion. Support for this interpretation exists in previous findings in IGT sub- jects. In particular, there is a progressive decline in the normally tight temporal coupling between glucose and insulin secretion as glucose tolerance deteriorates from normal to IGT to frank diabetes [6]. We previously reported that this defect, present in those with IGT, improves after treatment with the insulinsensitizing agent troglitazone [25, 26].

Glucose minimal model analysis can also be done on the same data to derive an index of insulin sensitivity. As a result, it becomes possible to evaluate the contribution of insulin secretion and insulin action from this single protocol. A number of parameters (so called disposition indices) were calculated as the product of $\mathrm{Si}$ and parameters of beta-cell function, to adjust the measures of insulin secretion for the degree of insulin sensitivity.

It is worth noting that the hyperbolic relationship between parameters of insulin sensitivity and of insulin secretion was first formulated [20] by using IVGTT minimal model derived indices for both insulin sensitivity and pancreatic sensitivity. In particular, indices of (post-hepatic) responsivity of the beta cell to glucose obtained by minimal model analysis of glucose and insulin data (here denoted as first phase $\phi_{1}{ }^{\text {post }}$ and second phase $\left.\phi_{2}{ }^{\text {post }}\right)$ were used. Subsequently the hyperbolic relationship was validated in a large group of normal glucose tolerant subjects by using a first phase index, $\mathrm{AIR}_{\text {glucose }}$, calculated as the mean increment above basal of insulin values measured at 2, 3, 4, 5, 6, 8 and 10 min after an intravenous glucose bolus $(300 \mathrm{mg} / \mathrm{kg})$ [19]. However, AIR $_{\text {glucose }}$, as well as $\phi_{1}{ }^{\text {post }}$ and $\phi_{2}{ }^{\text {post }}$ are indices of post-hepatic insulin secretion, thus reflecting both pancreatic secretion and hepatic extraction. Moreover, $\mathrm{AIR}_{\text {glucose }}$ also depends on plasma clearance rate (being derived directly from the insulin data without using any kind of modelling) and is based on an empiric definition of the first phase as occurring in the time interval of 0 to 10 min after the bolus injection.

The indices we used in this study, i.e. $\phi_{\mathrm{d}}$ and $\phi_{\mathrm{s}}$, were obtained by modelling C-peptide and glucose data and provide a better measure of beta-cell function because they reflect pancreatic insulin secretion without the confounding effects of hepatic extraction and C-peptide kinetics. Moreover the separation between the two phases of insulin secretion, dynamic, analogous to the first phase, and static, analogous to the second phase, is not arbitrary, because the two phases are superimposed but the minimal model indices are able to quantify them separately.

When insulin secretion was analysed in relation to the degree of insulin resistance it became evident that the insulin secretory response was inadequate for the degree of insulin resistance among the Obese-IGT subjects. This is reflected in significantly lower disposition indices among the Obese-IGT. The $\mathrm{Si} \times$ ISR product was approximately $43 \%$ of that observed in the Obese-NGT subjects and $29 \%$ of that 
in Controls in the step-up phase. Similarly, in the step-down phase, the Si x ISR product in the ObeseIGT group was $65 \%$ and $40 \%$ of that in the stepdown phase of their respective comparison groups. These results suggest that maintenance of normal glucose tolerance in obesity results, at least in part, from an increase in beta-cell sensitivity to glucose to compensate the decrease in insulin sensitivity. Additional evidence to support a relative defect in the ability to adequately compensate for insulin resistance in IGT comes from the finding that the disposition indices $\mathrm{Si} \times \phi_{\mathrm{d}}$ and $\mathrm{Si} \times \phi_{\mathrm{s}}$ were lower in the $\mathrm{Ob}$ ese-IGT subjects compared to both Controls and Obese-NGT subjects (the differences among $\mathrm{Si} \times \phi_{\mathrm{s}}$ were statistically significant). In other words these data indicate that the development of impaired glucose tolerance in obesity occurs in the setting of a reduction in beta-cell sensitivity to glucose normalized for the degree of insulin sensitivity and are consistent with previous findings in IGT using a frequently sampled IVGTT or step-up only protocol [25-28]. Of note, failure to detect significant differences in all disposition indices between Obese-NGT and Obese-IGT groups could have resulted, at least in part, from the fact that the groups were comprised of 6 subjects each. This group size potentially limited the power to detect true differences in some measures relating insulin secretion to insulin action (i.e., disposition indices) when they may have, in fact, existed.

In conclusion, application of both deconvolution and C-peptide minimal models to data provided by a novel glucose infusion protocol has shown that individuals with impaired glucose tolerance are characterized by a relative defect in the ability to secrete insulin to adequately compensate for insulin resistance. The more detailed portrait of beta-cell function obtained by the $\mathrm{C}$-peptide model analysis also revealed delays in the timing of the beta-cell response to glucose that are present when glucose levels are either rising or falling. Taken together, the defects in insulin secretion detected by the present methods probably contribute to the pathogenesis of impaired glucose tolerance.

Acknowledgements. These studies were supported in part by DK-02315, DK-31842, DK-20595, DK-02742, HD-06308, DK07011-17, General Clinical Research Center MO1 RR00 055.

\section{References}

1. Report of the Expert Committee on the Diagnosis and Classification of Diabetes Mellitus. Diabetes Care 20: 1183-1197

2. Edelstein S, Knowler W, Bain R et al. (1997) Predictors of progression from impaired glucose tolerance to NIDDM. Diabetes 46: 701-710

3. Polonsky K, Sturis J, Bell G (1996) Non-insulin-dependent diabetes mellitus - a genetically programmed failure of the beta cell to compensate for insulin resistance. N Engl J Med 334: 777-783

4. Byrne M, Sturis J, Polonsky K (1995) Insulin secretion and clearance during low-dose graded glucose infusion. Am J Physiol 268: E21-E27

5. Ehrmann D, Sturis J, Byrne M, Karrison T, Rosenfield R, Polonsky K (1995) Insulin secretory defects in polycystic ovary syndrome: relationship to insulin sensitivity and family history of non-insulin dependent diabetes mellitus. J Clin Invest 96: 520-527

6. O’Meara N, Sturis J, Van Cauter E, Polonsky K (1993) Lack of control by glucose of ultradian insulin secretory oscillations in impaired glucose tolerance and in non-insulin-dependent diabetes mellitus. J Clin Invest 92: 262-271

7. Sturis J, Van Cauter E, Blackman J, Polonsky K (1991) Entrainment of pulsatile insulin secretion by oscillatory glucose infusion. J Clin Invest 87: 439-445

8. Sturis J, Polonsky K, Shapiro E, Blackman J, O’Meara N, Van Cauter E (1992) Abnormalities in the ultradian oscillations of insulin secretion and glucose levels in Type II (noninsulin-dependent) diabetic patients. Diabetologia 35: 681-689

9. Toffolo G, Breda E, Cavaghan M, Ehrmann D, Polonsky K (2001) Quantitative indices of $\beta$-cell function during up and down graded glucose infusion from $C$-peptide minimal models. Am J Physiol Endocrinol Metab 280: 2-10

10. Valdes C, Elkind-Hirsch K (1991) Intravenous glucose tolerance test-derived insulin sensitivity changes during the menstrual cycle. J Clin Endocrinol Metab 72: 642-646

11. Diamond M, Simonson D, DeFronzo R (1989) Menstrual cyclicity has a profound effect on glucose homeostasis. Fertil Steril 52: 204-208

12. Bergman RN, Ider YZ, Bowden CR, Cobelli C (1979) Quantitative estimation of insulin sensitivity. Am J Physiol 236: E667-E677

13. Van Cauter E, Mestrez F, Sturis J, Polonsky K (1992) Estimation of insulin secretion rates from C-peptide levels. Comparison of individual and standard kinetic parameters for C-peptide clearance. Diabetes 41: 368-377

14. Polonsky K, Licinio-Paixao J, Given B et al. (1986) Use of biosynthetic human C-peptide in the measurement of insulin secretion rates in normal volunteers and Type I diabetic patients. J Clin Invest 77: 98-105

15. Toffolo G, De Grandi F, Cobelli C (1995) Estimation of beta-cell sensitivity from intravenous glucose tolerance test C-peptide data. Knowledge of the kinetics avoids errors in modeling the secretion. Diabetes 44: 845-854

16. Breda E, Cavaghan MC, Toffolo G, Polonsky KS, Cobelli C (2001) Oral Glucose Tolerance Test Minimal Model Indexes of $\beta$-Cell Function and Insulin Sensitivity, Diabetes 50: $150-158$

17. Grodsky G (1972) A threshold distribution hypothesis for packet storage of insulin and its mathematical modeling. J Clin Invest 51: 2047-2059

18. Barrett PH, Bell BM, Cobelli C et al. (1998) SAAM II: Simulation, Analysis, and Modeling Software for tracer and pharmacokinetic studies. Metabolism 47: 484-492

19. Kahn S, Prigeon R, McCulloch D et al. (1993) Quantification of the relationship between insulin sensitivity and Bcell function in human subjects Evidence for a hyperbolic function. Diabetes 42: 1663-1672

20. Bergman RN, Phillips LS, Cobelli C (1981) Physiologic evaluation of factors controlling glucose tolerance in man. Measurement of insulin sensitivity and beta-cell function from the response to intravenous glucose. J Clin Invest 68: 1456-1467 
21. Carson ER, Cobelli C, Finkelstein L (1983) The Mathematical Modeling of Metabolic and Endocrine Systems. Wiley, New York

22. Cobelli C, Foster D, Toffolo G (2000) Tracer Kinetic in Biomedical Research: from Data to Model, Kluwer Academic/Plenum, New York

23. Morgan C, Lazarow A (1963) Immunoassay of insulin: two antibody systems: plasma insulin levels of normal, subdiabetic and diabetic rats. Diabetes 12: 115-126

24. Faber O, Binder C, Markussen J et al. (1978) Characterization of seven C-peptide antisera. Diabetes 27: 170-177

25. Cavaghan MK, Ehrmann DA, Byrne MM, Polonsky KS (1999) Treatment with the oral antidiabetic agent troglitazone improves beta cell responses to glucose in subjects with impaired glucose tolerance. J Clin Invest 100: 530-537
26. Ehrmann DA, Schneider DJ, Sobel BE et al. (1997) Troglitazone improves defects in insulin action, insulin secretion, ovarian steroidogenesis and fibrinolysis in women with polycystic ovary syndrome J Clin Endocrinol Metab 82: 2108-2116

27. Weyer C, Bogardus C, Mott DM, Pratley RE (1999) The natural history of insulin secretory dysfunction and insulin resistance in the pathogenesis of type 2 diabetes mellitus. J Clin Invest 104: 787-794

28. Buchanan TA, Xiang AH, Kjos SL, Trigo E, Lee WP, Peters RK (1999) Antepartum predictors of the development of type 2 diabetes in Latino women 11-26 months after pregnancies complicated by gestational diabetes. Diabetes 48: 2430-2436 